\section{Human Bartonella Infective Endocarditis is Associated with High Frequency of Antiproteinase 3 Antibodies}

\section{To the Editor:}

Bartonella henselae and B. quintana are the 2 Bartonella species most commonly involved in human disease and are associated with the formation of vasoproliferative tumors ${ }^{1}$. Chronic infections are bacteremia (particularly affecting homeless patients), endocarditis, bacillary angiomatosis, and liver peliosis ${ }^{2}$. Antineutrophil cytoplasmic antibody (ANCA)-associated vasculitides are a group of diseases characterized by necrotizing vasculitis of small vessels and associated with autoantibodies against neutrophil constituents such as myeloperoxidase (MPO) and proteinase $3(\mathrm{PR} 3)^{3}$. Granulomatosis with polyangiitis (GPA), microscopic polyangiitis (MP), and Churg-Strauss syndrome (CSS) are all forms of vasculitis associated with anti-PR3. Several chronic infectious diseases (mycobacterial infections, chronic hepatitis $\mathrm{C}$ virus infection, and amoebic liver abscess) have been reported to be associated with a positive ANCA by immunofluorescence, but the specificity was not always defined by ELISA-testing specificity ${ }^{4}$. A few cases of subacute endocarditis have been reported to be associated with ANCA positivity, mainly anti-PR3.

A 40-year-old homeless man was admitted for aortic endocarditis due to Bartonella, associated with high anti-PR3 antibody titers (110 IU/l, normal < 20 IU). Retrospectively, we looked for ANCA positivity (indirect immunofluorescence using ethanol-fixed fresh normal neutrophils) and anti-MPO and anti-PR3 antibodies in sera from 46 consecutive cases of infective endocarditis: 22 scored as gram-positive definite endocarditis and 25 were diagnosed as having Bartonella endocarditis on the basis of serology 5 and/or sequencing of the $16 \mathrm{~S}$ rDNA from heart valves ${ }^{6}$ (Table 1). The indirect immunofluorescence detection method revealed cytoplasmic ANCA positivity in 20 of our 47 patients (46 plus our case). Five of these positive cases were in the gram-positive endocarditis group (22.7\%) and 15 in the Bartonella endocarditis group (60\%; Table 2). The ELISA detection method for anti-PR3 antibodies scored positive for $1(4.5 \%)$ and $10(40 \%)$ patients, respectively, in the gram-positive endocarditis group and in the Bartonella endocarditis group ( $\mathrm{p}=0.0053)$. One patient was positive for both anti-PR3 and anti-MPO antibodies in the Bartonella endocarditis group. Staphylococcus aureus was the pathogen implicated in the positivity of anti-PR3 antibodies in the gram-positive endocarditis group. Bartonella serology testing was negative in all sera of the gram-positive endocarditis group. In cases of Bartonella endocarditis, anti-PR3 antibodies are probably more a marker than an effector of vascular inflammation.

ANCA-associated vasculitides are characterized by necrotizing inflammation of the walls of the small arteries, venules, arterioles, and capillaries. PR3 ANCA are positive in about $80 \%$ of patients with GPA and $35 \%$ of patients with MP or CSS. The prevalence of PR3-ANCA in patients with GPA depends greatly on the vasculitis disease activity and the extent of vasculitis. In our case, anti-PR3 positivity was only associated with the active phase of the infection, and the titer fell below the threshold of detection after the endocarditis was cured. This frequent association of anti-PR3 or anti-MPO antibodies with vasculitides has led to the assumption that ANCA are directly involved in the pathogenesis of these diseases. Less is known about the pathogenesis of ANCA-associated vasculitides (AAV), and particularly that of anti-PR3-ANCA vasculitides ${ }^{7}$. In vitro experiments have demonstrated activation of neutrophils by

Table 1. Indirect immunofluorescence and specificity of ANCA testing in the 25 Bartonella endocarditis group.

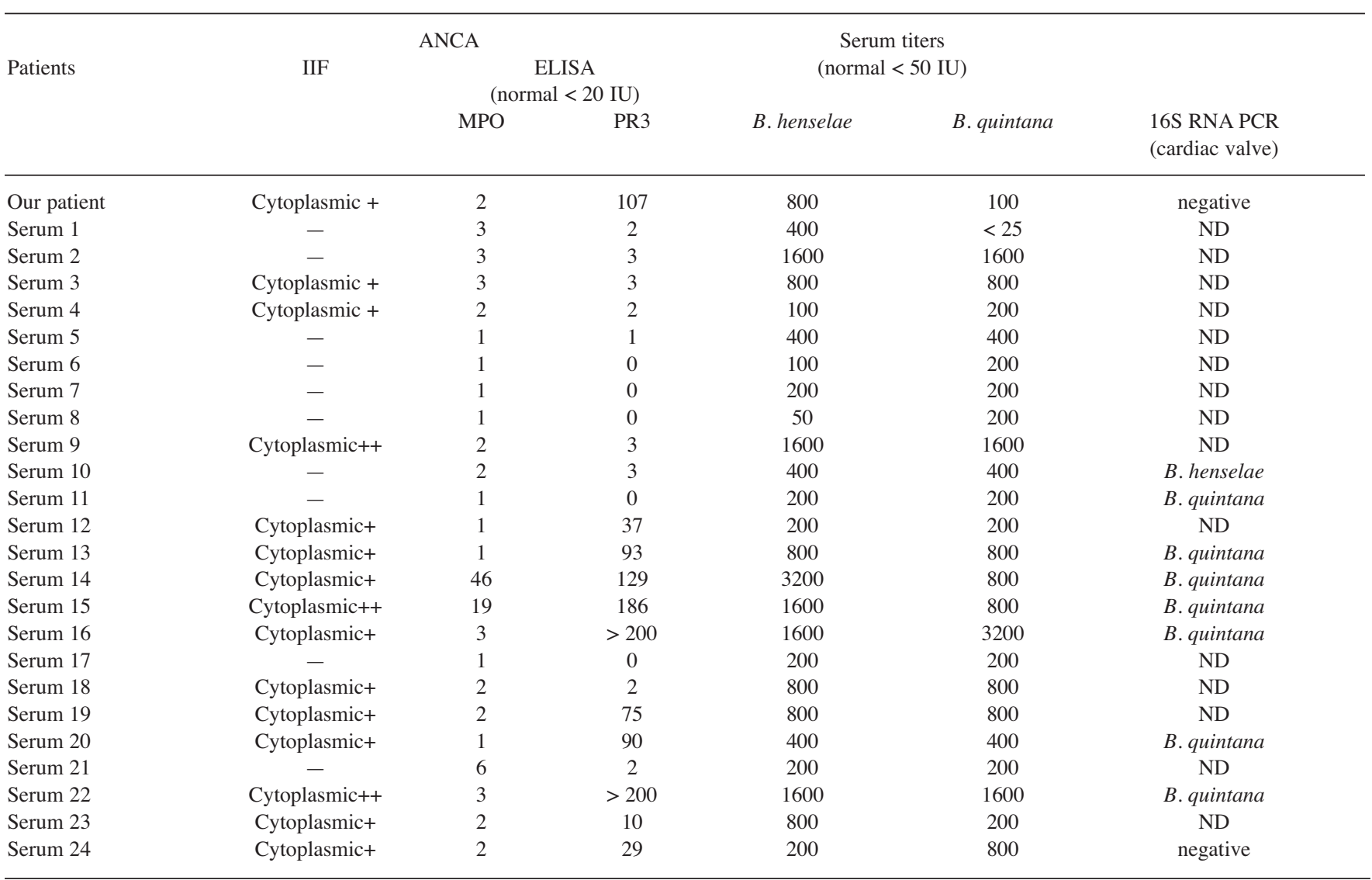

Cytoplasmic + refers to a positive fluorescence (titers about $40 \mathrm{IU} / \mathrm{ml}$ ), and cytoplasmic ++ refers to a high positive fluorescence (titers about $160 \mathrm{IU} / \mathrm{ml}$ ). ANCA: antineutrophil cytoplasmic antibodies; IIF: indirect immunofluorescence; MPO: myeloperoxidase; PR3: proteinase 3; ND: not determined. 
Table 2. Indirect immunofluorescence and specificity of ANCA testing in the 22 gram-positive endocarditis group.

\begin{tabular}{|c|c|c|c|}
\hline \multirow[t]{2}{*}{ Endocarditis Pathogen } & \multirow[t]{2}{*}{ IIF } & \multicolumn{2}{|c|}{$\begin{array}{l}\text { ANCA } \\
\text { ELISA (normal < } 20 \text { IU) }\end{array}$} \\
\hline & & MPO & PR3 \\
\hline Staphylococcus aureus & - & 3 & 1 \\
\hline S. aureus & Cytoplasmic+ & 3 & 2 \\
\hline S. aureus & - & 5 & 1 \\
\hline S. aureus & - & 3 & 1 \\
\hline Staphylococcus epidermidis & - & 3 & 1 \\
\hline S. aureus & - & 3 & 1 \\
\hline S. aureus & Cytoplasmic+ & 3 & 2 \\
\hline S. aureus & - & 4 & 3 \\
\hline S. aureus & - & 4 & 3 \\
\hline S. aureus & Cytoplasmic+ & 9 & 28 \\
\hline S. aureus & - & 3 & 2 \\
\hline Streptococcus sanguinis & - & 3 & 2 \\
\hline Streptococcus mitis & - & 2 & 1 \\
\hline S. mitis & Cytoplasmic+ & 2 & 1 \\
\hline Streptococcus gordonii & - & 4 & 5 \\
\hline Streptococcus dysgalactiae & - & 3 & 1 \\
\hline S. sanguinis & - & 3 & 2 \\
\hline S. mitis & - & 3 & 1 \\
\hline Enterococcus faecalis & - & 3 & 2 \\
\hline E.faecalis & - & 3 & 2 \\
\hline E. faecalis & - & 2 & 3 \\
\hline E. faecalis & Cytoplasmic+ & 3 & 5 \\
\hline
\end{tabular}

Cytoplasmic + refers to a positive fluorescence (titers about $40 \mathrm{IU} / \mathrm{ml}$ ), and cytoplasmic ++ refers to a high positive fluorescence (titers about $160 \mathrm{IU} / \mathrm{ml}$ ). . ANCA: antineutrophil cytoplasmic antibodies; IIF: indirect immunofluorescence; MPO: myeloperoxidase; PR3: proteinase 3.

PR3-ANCA, with oxidative bursts and the release of lytic enzymes including elastase and PR3. The role of microbes has also been suggested. Chronic nasal carriage of $S$. aureus is associated with a higher relapse rate, and prophylactic treatment with cotrimoxazole can prevent relapse in cases of $\mathrm{GPA}^{8}$.

Endocarditis associated with ANCA remains very rare: 18 reported cases, mostly due to gram-positive endocarditis and with an anti-PR3 specificity. Bartonella endocarditis shares 2 characteristics with PR3-AAV: they are chronic diseases involving endothelial cells. The extent of endothelium involvement is larger in cases of Bartonella (diffuse endothelial cells of blood vessels) than in subacute bacterial endocarditis (endocardium of the cardiac valves). The Bartonella species implicated in human endocarditis have a specific tropism for endothelial cells and enhance vascular neoproliferation by induction of the proliferation of endothelial cells, inhibition of their apoptosis, or production of vascular endothelial growth factor by infected macrophages 9 .

Bartonella infection of endothelium results in the release of chemoattractants, mostly interleukin 8 , resulting in recruitment of circulating polymorphonuclear leukocytes (PMN) and monocytes/macrophages to the site of infection ${ }^{9,10}$. Further, the apoptotic behavior of isolated human neutrophils is delayed by the presence of $B$. quintana lipopolysaccharide ${ }^{10}$. Therefore, it is possible that during delayed PMN apoptosis induced by Bartonella, PR3 remains in contact with the host immune system longer and stimulates increased production of anti-PR3 antibodies.

PR3-AAV and Bartonella endocarditis exhibit high prevalences of anti-PR3 antibodies positivity.

ELISABETH ASLANGUL, MD, PhD, Université Paris Descartes and AP-HP, Hôtel Dieu, Internal Medicine Unit; CLAIRE GOULVESTRE, MD, AP-HP, Hôpital Cochin, Paris, France; ZIAD MALLAT, MD, PhD, INSERM U970, Paris, France, and Department of Medicine, University of Cambridge, Cambridge, UK; JEAN-LUC MAINARDI, MD, PhD, Centre de Recherche des Cordeliers, LRMA, Equipe 12, Université Paris Descartes, Sorbonne Paris Cité, UMR S 872; Université Pierre et Marie Curie; INSERM U872; AP-HP, Hôpital Européen Georges Pompidou, Paris, France. Address correspondence to Dr. E. Aslangul, Internal Medicine Department, Hôtel Dieu 1, Place du Parvis Notre Dame, 75004 Paris, France. E-mail: elisabeth.aslangul@htd.aphp.fr

\section{REFERENCES}

1. Harms A, Dehio C. Intruders below the radar: molecular pathogenesis of Bartonella spp. Clin Microbiol Rev 2012;25:42-78.

2. Foucault C, Brouqui P, Raoult D. Bartonella quintana characteristics and clinical management. Emerg Infect Dis 2006; $12: 217-23$.

3. Jennette JC. Nomenclature and classification of vasculitis: lessons learned from granulomatosis with polyangiitis (Wegener's granulomatosis). Clin Exp Immunol 2011;164 Suppl 1:7-10.

4. Elkayam O, Bendayan D, Segal R, Shapira Y, Gilburd B, Reuter S, et al. The effect of anti-tuberculosis treatment on levels of anti-phospholipid and anti-neutrophil cytoplasmatic antibodies in patients with active tuberculosis. Rheumatol Int 2013;33:949-53.

5. Gouriet F, Samson L, Delaage M, Mainardi JL, Meconi S, Drancourt M, et al. Multiplexed whole bacterial antigen microarray, a new format for the automation of serodiagnosis: the culture-negative endocarditis paradigm. Clin Microbiol Infect 2008; 14:1112-8.

6. Podglajen I, Bellery F, Poyart C, Coudol P, Buu-Hoi A, Bruneval P, et al. Comparative molecular and microbiologic diagnosis of bacterial endocarditis. Emerg Infect Dis 2003;9:1543-7.

7. Kallenberg CG. Pathogenesis of PR3-ANCA associated vasculitis. J Autoimmun 2008;30:29-36. 
8. Stegeman CA, Tervaert JW, Kallenberg CG. Anti-neutrophil cytoplasmic antibodies: tools for diagnosis and follow-up in systemic vasculitis. Ann Med Interne 1994;145:523-32.

9. Dehio C. Recent progress in understanding Bartonella-induced vascular proliferation. Curr Opin Microbiol 2003;6:61-5.
10. Matera G, Liberto MC, Quirino A, Barreca GS, Lamberti AG, Iannone $\mathrm{M}$, et al. Bartonella quintana lipopolysaccharide effects on leukocytes, CXC chemokines and apoptosis: a study on the human whole blood and a rat model. Int Immunopharmacol 2003;3:853-64.

J Rheumatol 2014;41:2; doi:10.3899/jrheum.130150 